\title{
Involvement of Hus1 in the chain elongation step of DNA replication after exposure to camptothecin or ionizing radiation
}

\author{
Xiang Wang, Jun Guan, Baocheng Hu, Robert S. Weiss ${ }^{1}$, George Iliakis ${ }^{2}$ and \\ Ya Wang*
}

Department of Radiation Oncology, Kimmel Cancer Center of Jefferson Medical College, Thomas Jefferson University, Philadelphia, PA 19107, USA, ${ }^{1}$ Department of Biomedical Sciences, Cornell University, Ithaca, NY 14853, USA and ${ }^{2}$ Institute of Medical Radiation Biology, University of Duisburg-Essen Medical School, 45122 Essen, Germany

Received November 3, 2003; Revised and Accepted December 23, 2003

\begin{abstract}
DNA damage-induced $S$ phase (S) checkpoint includes inhibition of both replicon initiation and chain elongation. The precise mechanism for controlling the two processes remains unclear. In this study, we showed that Hus1-deficient mouse cells had an impaired $S$ checkpoint after exposure to DNA strand break-inducing agents such as camptothecin (CPT) $(\geqslant 1.0 \mu \mathrm{M})$, or ionizing radiation (IR) ( $\geqslant 15$ Gy). The Hus1-dependent $S$ checkpoint contributes to cell resistance to CPT. This impaired S checkpoint induced by CPT or IR in Hus1-deficient cells reflected mainly the chain elongation step of DNA replication and was correlated with the reduction of dissociation of PCNA from DNA replication foci. Although Hus1 is required for Rad9 phosphorylation following exposure of cells to CPT or IR, Hus1-deficient cells showed normal activation of ATR/CHK1 and ATM kinases at doses where the checkpoint defects were manifested, suggesting that Hus1 is not a component of the sensor system for activating these pathways in $S$ checkpoint induced by CPT or IR.
\end{abstract}

\section{INTRODUCTION}

In response to DNA damage, proliferating cells slow their progress through the $S$ phase (a transient inhibition of DNA replication) via activation of the $S$ phase (S) checkpoint (1-4), which is measured as a decrease in $\left[{ }^{3} \mathrm{H}\right]$ thymidine incorporation into total DNA $(5,6)$. The DNA damage-induced inhibition of DNA replication includes both replicon initiation and chain elongation, which is measured as a decrease in $\left[{ }^{3} \mathrm{H}\right]$ thymidine incorporation into the different sizes of newly synthesized DNA (7-12). Replicon initiation is much more sensitive than chain elongation to DNA damage inducers. For example, the dose-response curves for ionizing radiation (IR)induced inhibition of DNA replication are biphasic with a steep component $\left(D_{0} \sim 10 \mathrm{~Gy}\right)$ that derives from the inhibition of replicon initiation and a shallow component $\left(\mathrm{D}_{0} \sim 100 \mathrm{~Gy}\right)$ that derives from the inhibition of chain elongation (7-9). It is generally believed that the inhibition of replicon initiation is controlled by the $\mathrm{S}$ checkpoint and the inhibition of chain elongation reflects only a passive cellular response. The precise mechanism of controlling the inhibition of the two processes, replicon initiation and chain elongation, however, remains unclear.

Hus1 is an important and conserved checkpoint protein. Hus1 forms a trimer complex with Rad1 and Rad9 (the 9-1-1 complex) to encircle DNA following DNA damage, which is structurally similar to the DNA sliding clamp protein PCNA, which recruits polymerase $\delta$ and serves as a processing factor during DNA synthesis (13-18). However, different from fission yeast, which lacks husl and appears normal under standard growth conditions (19), mammalian without Husl is lethal (20), suggesting that mammalian Husl mediates additional and essential functions not performed by fission yeast hus1. Mammalian Hus1 could interact directly with PCNA in response to DNA damage (21), but the function of this interaction between these two proteins remains unclear.

Hus1 is involved in UV-induced S checkpoint via affecting activation of the ATR/CHK1 pathway $(22,23)$. Camptothecin (CPT) as a DNA strand break inducer could induce the strong $S$ checkpoint response in mammalian cells and this $S$ checkpoint is regulated mainly by the ATR/CHK1 pathway (24-28). It is not known, however, whether Hus 1 plays any role in CPT-induced $\mathrm{S}$ checkpoint. There is no apparent difference in the inhibition of DNA replication between Hus 1 wild type and Hus1-deficient mammalian cells following

*To whom correspondence should be addressed. Tel: +1 215955 2045; Fax: +1 215955 2052; Email: ya.wang@mail.tju.edu

Present addresses:

Jun Guan, Department of Radiation Oncology, University of Pennsylvania, Philadelphia, PA 19104, USA

Baocheng Hu, Beijing Institute of Biotechnology, Beijing 100850, China

The authors wish it to be known that, in their opinion, the first three authors should be regarded as joint First Authors

Nucleic Acids Research, Vol. 32 No. 2 (C) Oxford University Press 2004; all rights reserved 
exposure to IR $\leqslant 10$ Gy (23), suggesting that Hus1 is not involved in IR-induced inhibition of replicon initiation. It is not known, however, whether Hus1 plays any role in IRinduced inhibition of chain elongation.

We show in this study that Hus1-deficient mouse fibroblasts have an impaired $\mathrm{S}$ checkpoint response after exposure to CPT $(\geqslant 1.0 \mu \mathrm{M})$ or IR ( $\geqslant 15 \mathrm{~Gy})$. The Hus1-involved S checkpoint contributes to CPT-sensitivity. An impaired S checkpoint in CPT-treated or irradiated Hus1-deficient cells is caused by a defect in the regulation of chain elongation and is associated with a defect in dissociation of PCNA from DNA replication foci. Although Hus1 is required for Rad9 phosphorylation following CPT treatment or IR, Hus1-deficient cells show normal activation of ATR/CHK1 or ATM kinase when an impaired $\mathrm{S}$ checkpoint occurs. These results indicate that similar to the inhibition of replicon initiation, DNA damageinduced inhibition of chain elongation of DNA replication is also a cellular active response. The role of Hus1 in the chain elongation process of $\mathrm{S}$ checkpoint induced by CPT or IR might relate to PCNA replication function. Taken together, our results suggest that Hus1 acts like a downstream effector but not like a sensor to activate the ATR/CHK1 or ATM pathway after exposure of cells to DNA strand break-inducers such as CPT or IR.

\section{MATERIALS AND METHODS}

\section{Cell lines, chemical treatment and irradiation}

Hus $1^{+/+} p 21^{-/-}$and Hus $1^{-/-} p 21^{-/-}$mouse embryonic fibroblasts (MEFs) (20), as well as the corresponding complemented cell pools (22), were cultured in Dulbecco's modified Eagle's medium (Dulbecco's MEM) supplemented with $10 \%$ fetal bovine serum, streptomycin sulfate $(100 \mu \mathrm{g} / \mathrm{ml})$ and penicillin $(100 \mathrm{U} / \mathrm{ml})$. The incubations were at $37^{\circ} \mathrm{C}$ in an atmosphere of $5 \% \mathrm{CO}_{2}$ and $95 \%$ air. Cells were either treated with CPT (NCS 100880, obtained from the National Cancer Institute) or exposed to X-rays (310 kV, $10 \mathrm{~mA}, 2 \mathrm{~mm} \mathrm{Al} \mathrm{filter).}$

\section{DNA replication assay}

Cells were plated at a density of $1 \times 10^{5}$ per dish $(60 \mathrm{~mm})$ and labeled for $48 \mathrm{~h}$ in medium containing $\left[{ }^{14} \mathrm{C}\right]$ thymidine at $10 \mathrm{nCi} / \mathrm{ml}$ (Perkin Elmer Life Science Products, Inc.), to provide an internal control for total DNA content. The cells were washed once with pre-warmed PBS and then were supplemented with pre-warmed non-radioactive medium. After cells were either treated with CPT for $3 \mathrm{~h}$ or at $3 \mathrm{~h}$ following IR, $\left[{ }^{3} \mathrm{H}\right]$ thymidine at $1 \mu \mathrm{Ci} / \mathrm{ml}$ (Perkin Elmer Life Science Products, Inc.) was added to the cell cultures for 30 min, and then the cells were collected. The following procedures were the same as described (29). The rate of DNA synthesis for each sample was calculated as ${ }^{3} \mathrm{H}$ d.p.m./ ${ }^{14} \mathrm{C}$ d.p.m. and presented as a percentage of the control values obtained from sham-irradiated cells.

\section{Flow cytometry measurement}

Cells were treated with $2 \mu \mathrm{M}$ CPT for $3 \mathrm{~h}$ and then were collected and fixed in $70 \%$ ethanol. Cells were stained with the solution $(62 \mu \mathrm{g} / \mathrm{ml}$ RNase A, $40 \mu \mathrm{g} / \mathrm{ml}$ propidium iodide and $0.1 \%$ Triton X-100 in phosphate-buffered saline buffer) at room temperature for $1 \mathrm{~h}$ as described (27). The distribution of cells in the cell cycle was measured in a flow cytometer (Coulter Epics Elite).

\section{Clonogenic survival assay}

Cellular sensitivity to CPT treatment was determined by the loss of colony-forming ability. In brief, $1 \times 10^{5}$ cells were plated per $60 \mathrm{~mm}$ dish with $3 \mathrm{ml}$ of medium. Two days later, cultures were supplemented with $2 \mu \mathrm{M}$ CPT for $8 \mathrm{~h}$. Cells were collected and plated, aiming at 20-200 colonies $/ 100 \mathrm{~mm}$ dish. Two replicates were prepared for each datum point and incubated for 1 week in the absence of drugs to allow colonies to develop. Colonies were stained with crystal violet $(100 \%$ methanol solution) before counting.

\section{Alkaline sucrose gradient sedimentation}

This method was used to determine the molecular weight distribution of newly synthesized DNA in either CPT-treated or irradiated cells. Linear sucrose gradients (5-20\%) were prepared in a buffer containing $0.1 \mathrm{M} \mathrm{NaOH}, 0.9 \mathrm{M} \mathrm{NaCl}$ and $10 \mathrm{mM}$ EDTA (pH 12.5) in polyallomer tubes. After Hus1 cells were either treated with $2 \mu \mathrm{M} \mathrm{CPT}$ for $3 \mathrm{~h}$ or at $3 \mathrm{~h}$ following $30 \mathrm{~Gy}$ exposure, $\left[{ }^{3} \mathrm{H}\right]$ thymidine at $5 \mu \mathrm{Ci} / \mathrm{ml}$ was added to the culture and kept for $15 \mathrm{~min}$. The following procedures are the same as described (30).

\section{Kinase activity assay}

After the cells were either treated with $2 \mu \mathrm{M} \mathrm{CPT}$ for $3 \mathrm{~h}$ or at $3 \mathrm{~h}$ following $30 \mathrm{~Gy}$ exposure, they were collected for preparing extracts. (i) ATR: ATR activity was examined with a chromatin-bound extract prepared as described previously (24). ATR antibody (sc-1887) was purchased from Santa Cruz Biotechnology, Inc. (ii) CHK1: the cells were collected for preparing nuclear extracts by using NE-PER ${ }^{\mathrm{TM}}$ kit (PIERCE) according to the manufacturer's instructions. The nuclear extracts $(250 \mu \mathrm{g})$ were then mixed with $1 \mu \mathrm{g}$ of $\mathrm{CHK} 1$ antibody (sc-163, Santa Cruz Biotechnology, Inc.) in the presence of $10 \mu \mathrm{l}$ of a $50 \%(\mathrm{v} / \mathrm{v})$ protein A-Sepharose slurry (RepliGen). The following procedures are similar to those described previously (24), except that kinase buffer without $\mathrm{NaCl}$ was used. (iii) $\mathrm{CDK} 2$ : the nuclear extracts $(250 \mu \mathrm{g})$ were mixed with $1 \mu \mathrm{g}$ of CDK2 antibody (sc-7898, Santa Cruz Biotechnology, Inc.) in the presence of $10 \mu \mathrm{l}$ of a $50 \%(\mathrm{v} / \mathrm{v})$ protein A-Sepharose slurry (RepliGen). The following procedures are the same as described in the previous report (27).

\section{Antibodies and immunoblotting}

The antibodies against CDC25A (sc-7389), Rad17 (sc-5613) and Rad9 (sc-8324) were purchased from Santa Cruz Biotechnology, Inc. The antibodies against phosphoserine 345 of CHK1 and phosphotyrosine 15 of CDK2 were purchased from Cell Signaling Technology. The antibody against phosphoserine 635 of $\operatorname{Rad} 17$ was a gift from Dr Elledge's laboratory (31). The antibodies against regular SMC1 and phosphoserine 966 of SMC1 were a gift from Dr Qin's laboratory (32). The antibodies against regular $\mathrm{H} 2 \mathrm{AX}$ and phosphorylated $\mathrm{H} 2 \mathrm{AX}(\gamma \mathrm{H} 2 \mathrm{AX})$ were purchased from Upstate Company. Whole cell lysates were prepared by directly lysing the same number of cells with RIPA lysis buffer $(50 \mathrm{mM}$ Tris-HCl, pH 7.4; $1 \%$ NP-40; $0.25 \%$ sodium deoxycholate; $150 \mathrm{mM} \mathrm{NaCl} ; 1 \mathrm{mM}$ EGTA; $1 \mathrm{mM}$ PMSF; 
$1 \mu \mathrm{g} / \mathrm{ml}$ each of aprotinin, leupeptin, pepstatin; $1 \mathrm{mM}$ $\mathrm{Na}_{3} \mathrm{VO}_{4} ; 1 \mathrm{mM} \mathrm{NaF}$ ). Immunoblotting was performed by standard methods and signal detection was by ECL-plus (Amersham Pharmacia Biotech).

\section{Immunofluorescence staining}

Cells were grown on glass coverslips in 35-mm dishes for $24 \mathrm{~h}$. After the cells were treated with CPT for $3 \mathrm{~h}$ or at $3 \mathrm{~h}$ following IR, the cells were prepared for immunofluorescence staining. Fixation and permeabilization were performed with $3.7 \%$ paraformaldehyde for $10 \mathrm{~min}$ followed by $0.3 \%$ Triton for $10 \mathrm{~min}$. Samples were blocked in $4 \%$ donkey serum in PBS at room temperature for $10 \mathrm{~min}$ and then were incubated with anti-PCNA (1 $\mu \mathrm{g} / \mathrm{ml}$ ) antibody (sc-56, Santa Cruz Biotechnology, Inc.) at $37^{\circ} \mathrm{C}$ for $1 \mathrm{~h}$. After extensive washing, samples were incubated in FITC-conjugated secondary antibodies (Jackson Immunoresearch Laboratories) at $37^{\circ} \mathrm{C}$ for 45 min. Images were obtained on a Zeiss LSM510 confocal microscope.

\section{RESULTS}

\section{An impaired $S$ checkpoint in Hus1-deficient cells exposed to CPT $(\geqslant 1.0 \mu \mathrm{M})$ or IR ( $\geqslant 15 \mathrm{~Gy})$}

The ATR/CHK1 pathway plays a major role in CPT-induced $\mathrm{S}$ checkpoint $(24,26,28)$ and plays an important role in IR-induced S checkpoint $(29,33)$. Mammalian Hus1 stimulates activation of the ATR/CHK1 pathway after DNA damage (22,31). Therefore, we were interested in learning if Hus1 participates in either CPT- or IR-induced S checkpoint. For this purpose, we examined the effect of Hus1 on CPT- or IR-induced S checkpoint by measuring DNA replication in CPT-treated or irradiated Hus1 cells. Mammalian cells deficient in Hus1 alone are lethal and cells deficient in both Hus1 and p21 are viable (20). Therefore, we used Hus1 and p21 double knock out cells in our experiments. The results showed that when compared with Hus1 wild type cells, Hus1deficient cells had less inhibition of DNA replication after either CPT treatment (Fig. 1A) or IR (Fig. 1B). The difference in the inhibition of DNA replication between Hus1 wild type and Hus1-deficient cells was dose dependent. With lower dose $(<0.5 \mu \mathrm{M}$ CPT or $<10 \mathrm{~Gy})$ treatment, there was no statistical difference in the inhibition of DNA replication between the two cell lines. The data obtained from irradiated Hus1 $(\leqslant 10 \mathrm{~Gy})$ cells are consistent with previous findings (23), and indicate that Hus1-deficient cells had a normal $\mathrm{S}$ checkpoint response following such a dose of IR exposure. When the dose was increased, however, the difference became larger. With $2 \mu \mathrm{M}$ CPT treatment or 40 Gy exposure, the difference reached its maximum (Fig. 1A and B) and a dose higher than those did not increase the difference further (data not shown). The flow cytometry data showed that after $2 \mu \mathrm{M}$ CPT treatment, the $\mathrm{S}$ phase ratio was much higher in Hus1 wild type cells than in Hus1-deficient cells (Fig. 1C), confirming that the DNA replication is more strongly inhibited in Hus1 wild type cells than in Hus1-deficient cells following CPT treatment. When Hus1 was reintroduced into Hus1deficient cells, more inhibition of DNA replication following CPT treatment or IR was observed (Fig. 1A and B), indicating
A
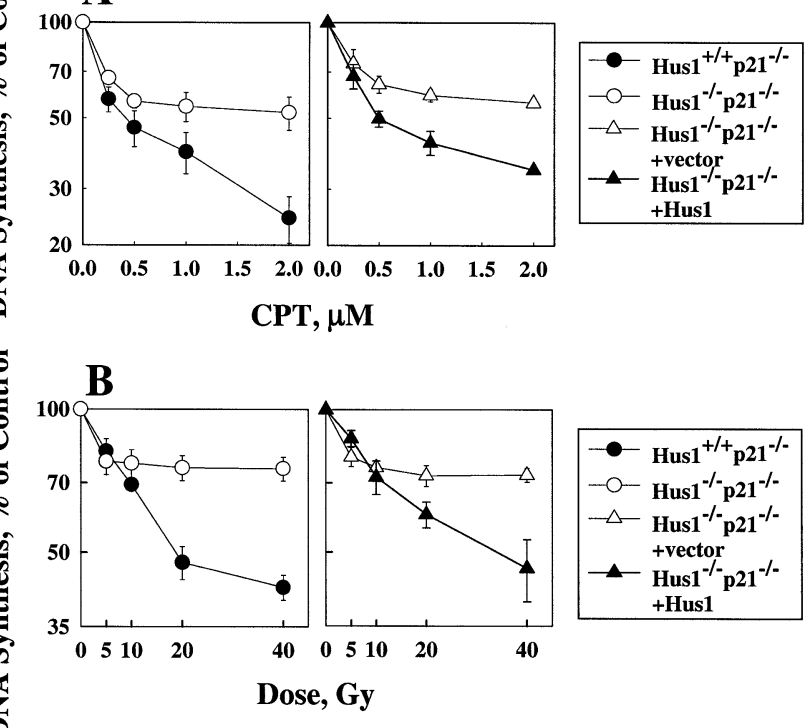

C
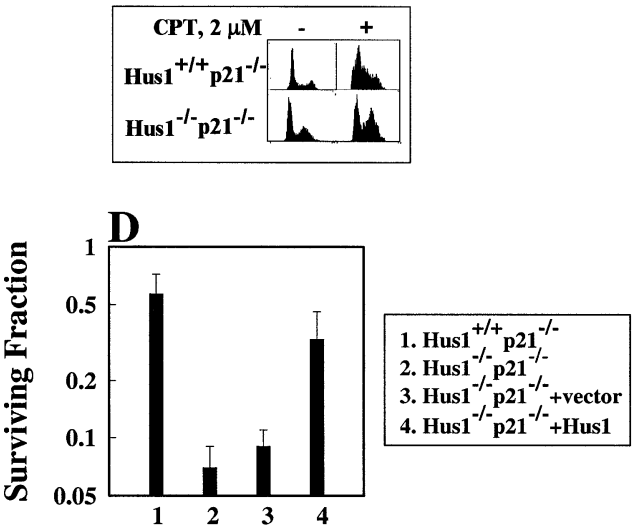

Figure 1. Hus1-deficient cells have an impaired S checkpoint response after exposure to CPT or IR. Hus $1^{-1-}$ MEFs fail to proliferate in culture, but inactivation of $p 21^{\text {wafl }}$ allows for the continued growth of $\mathrm{Hus}^{-1^{--}}$cells $(20)$. As described in Materials and Methods, ${ }^{14} \mathrm{C}$-pre-labeled cells were irradiated with different doses. $\left[{ }^{3} \mathrm{H}\right]$ Thymidine at $1 \mu \mathrm{Ci} / \mathrm{ml}$ was added to the cell cultures at $3 \mathrm{~h}$ after treatment with CPT $(\mathbf{A})$ or IR $(\mathbf{B})$. The rate of DNA synthesis was calculated as ${ }^{3} \mathrm{H}$ d.p.m. $/{ }^{14} \mathrm{C}$ d.p.m. for the various samples and was presented as a percentage of the values obtained from non-treated cells. Data shown are the average from three independent experiments. (C) Cell cycle distribution in CPT-treated Hus1 cells. As described in Materials and Methods, the Hus1 cells were treated with CPT $(2 \mu \mathrm{M})$ for $3 \mathrm{~h}$ and then were collected and prepared for flow cytometry measurement. (D) Cells were treated with $2 \mu \mathrm{M}$ CPT for $8 \mathrm{~h}$, then were collected and plated, aiming at $20-200$ colonies/100 mm dish. Two replicates were prepared for each datum point and incubated for 1 week in the absence of drugs to allow colonies to develop. Colonies were stained with crystal violet (100\% methanol solution) before counting. Data shown are the average from three independent experiments.

that the $\mathrm{S}$ checkpoint defect in Hus1-deficient cells is because of the absence of Hus1.

\section{The Hus1-dependent S checkpoint contributes to CPT resistance}

We reported previously that the $\mathrm{S}$ checkpoint regulated by the ATR/CHK1 pathway contributes to CPT resistance (27). Hus1 


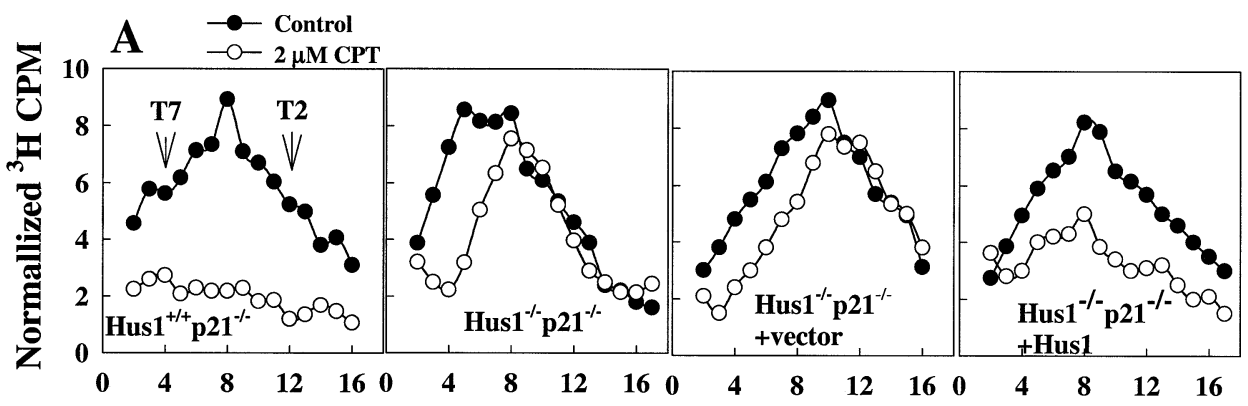

Fraction Number

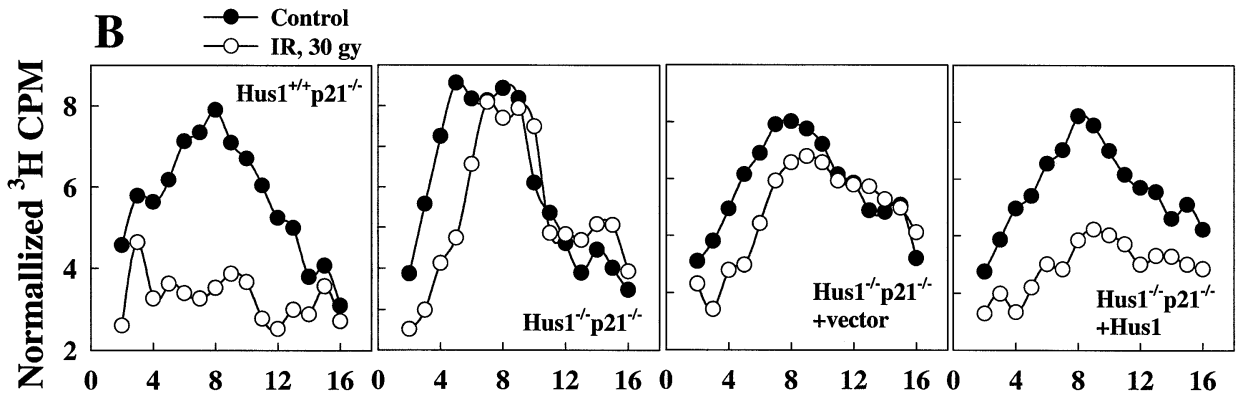

Fraction Number

Figure 2. Hus1-deficient cells display impaired inhibition of chain elongation of DNA replication following exposure to CPT or IR. The experimental process of alkaline sucrose gradient centrifugation was as described previously (30). Alkaline sedimentation profiles of nascent DNA from $\mathrm{Hus}^{+/+} p 2 \mathrm{I}^{{ }^{-/}}$and $\mathrm{Hus} \mathrm{I}^{-/-}$ $p 21^{-/}$cells without treatment (filled circle) as well as exposure to (open circle) either $2 \mu \mathrm{M} \mathrm{CPT}(\mathbf{A})$ or IR with 30 Gy (B) were analyzed. DNA synthesis is plotted according to the percentage of ${ }^{3} \mathrm{H}$ incorporation as a function of fraction number after consideration of the effect of CPT or IR on total DNA synthesis. Sedimentation is from left to right. Early fractions contain small nascent DNA produced at very early stages of DNA replication, and their reduction after irradiation reflects an inhibition of replicon initiation. Late fractions contain large nascent DNA produced at the later stages of DNA replication, and their reduction after irradiation reflects the inhibitions of both replicon initiation and chain elongation. T2 $(167 \mathrm{~kb})$ and T7 (37 kb) phage DNA are shown in the figure to indicate the sedimentation distances.

involves the regulation of CPT-induced $\mathrm{S}$ checkpoint, suggesting that Hus1 also contributes to CPT resistance. To test this hypothesis, we examined CPT sensitivity in these Hus1 cells. The results showed that the Hus1-deficient cells were more sensitive to CPT-induced killing than were the Hus1 wild type cells (Fig. 1D). When Hus1 was reintroduced into Hus1-deficient cells, the cells became resistant to CPT treatment (Fig. 1D), indicating that the sensitivity to CPT-induced killing shown in Hus1-deficient cells is because of the absence of Hus1. These results suggest that the Hus1-dependent $\mathrm{S}$ checkpoint protects cells from CPTinduced killing, further confirming the importance of CPTinduced S checkpoint for cellular resistance to CPT cytotoxicity (27). We then studied how Hus1 affected the S checkpoint.

\section{The defective $S$ checkpoint induced by CPT or IR in Hus1-deficient cells reflects a failure to inhibit the elongation step of DNA replication}

Velocity sedimentation analysis of pulse-labeled DNA reveals the steady-state distribution of nascent DNA intermediates in the S-phase cells, which can be used to estimate the distribution of replicon initiation and chain elongation (7-12). Therefore, to learn how Hus1 was involved in which process of DNA replication, replicon initiation or chain elongation following exposure of cells to CPT or IR, we used alkaline sucrose density centrifugation to specifically evaluate CPT- or IR-induced inhibition of DNA replication in Hus1-deficient cells. After exposure to CPT $(2 \mu \mathrm{M})$ or IR (30 Gy), Hus1 wild type cells showed an inhibition of both replicon initiation (manifested by a reduction in the activity in early fractions that represent the top of the gradient with low molecular weight material) and chain elongation (manifested by a reduction in the activity in late fractions that represent the bottom of the gradient with high molecular weight material) of DNA replication (Fig. 2). Hus1-deficient cells only showed an inhibition of replicon initiation and did not show any inhibition of chain elongation (Fig. 2). When Hus1 was reintroduced into Hus1-deficient cells, more inhibition of chain elongation following exposure of cells to CPT $(2 \mu \mathrm{M})$ or IR (30 Gy) was observed (Fig. 2), indicating that the deficient inhibition of chain elongation in Hus1-deficient cells is because of the absence of Hus1. These results indicate that, similar to DNA damage-induced inhibition of replicon initiation of DNA replication, the inhibition of chain elongation also is a cellular active response.

\section{Hus1 affects the replication foci of PCNA in CPT- treated or irradiated cells}

We next studied how Hus1 affected chain elongation during DNA replication in CPT-treated or irradiated cells. Hus1 interacts directly with PCNA in cells exposed to IR (21). We 
A
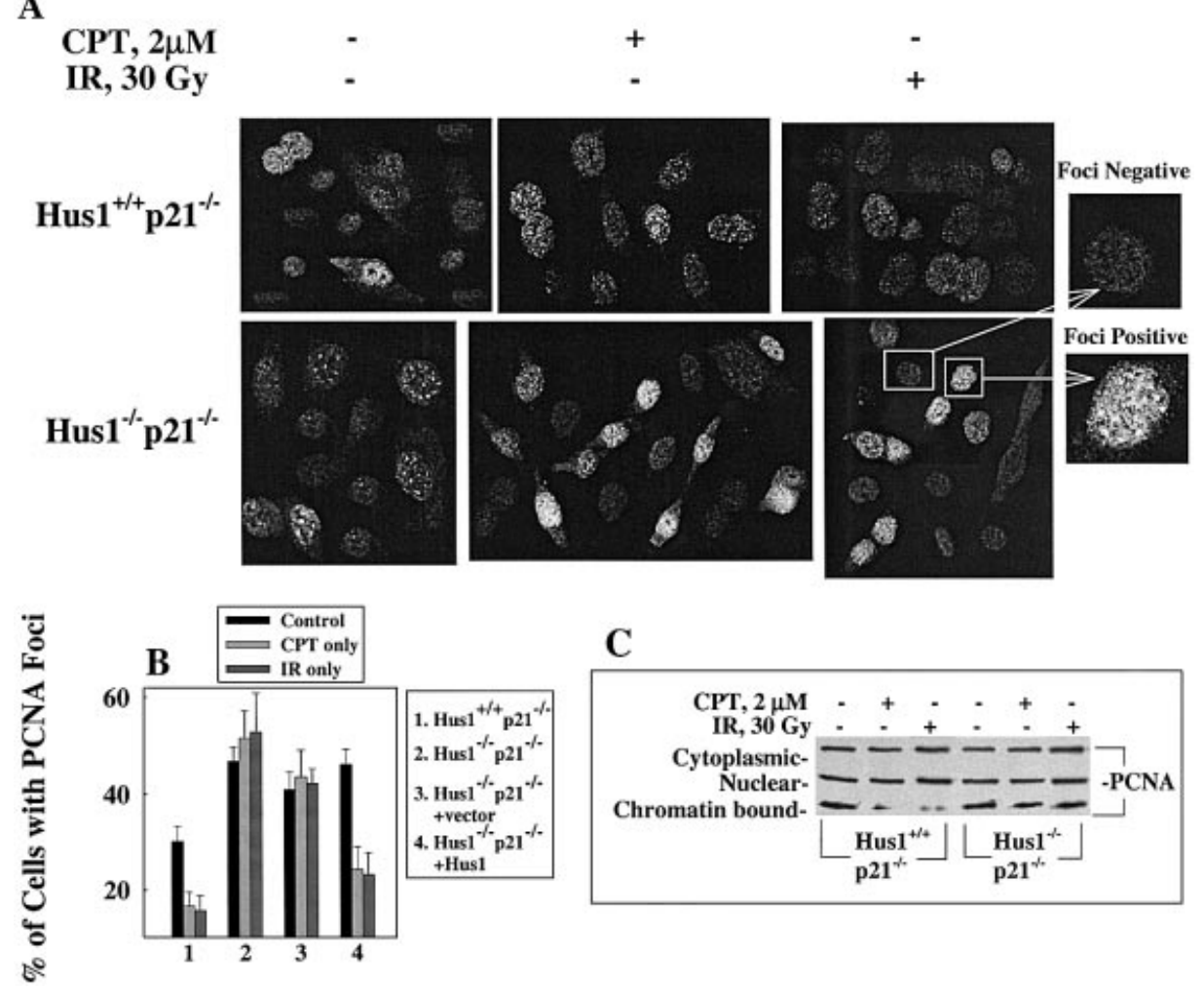

Figure 3. Hus 1 interferes with PCNA in DNA replication following exposure of cells to CPT or IR. (A) PCNA foci in Hus $1^{+/+} \mathrm{p} 21^{-/-}$and Hus $1^{-/} \mathrm{p} 21^{-/-}$cells treated with $2 \mu \mathrm{M}$ CPT for $3 \mathrm{~h}$ or irradiated with $30 \mathrm{~Gy}$. Hus 1 cells were grown on glass cover slips in $35 \mathrm{~mm}$ dishes for $24 \mathrm{~h}$. The cells were prepared for immunofluorescence staining $3 \mathrm{~h}$ after exposure to CPT or IR. Images were obtained on a Zeiss LSM510 confocal microscope. Magnified ones show the PCNA foci negative and positive cells. (B) Interpretation of the immunofluorescence images shown in (A). A minimum of 200 cells was analyzed for each experiment and results are presented as the average of three independent cell preparations. (C) The cytoplasmic, nuclear and chromatin-bound extracts were prepared as described in Materials and Methods. Western blot was performed to detect the PCNA signal.

were interested in discovering whether this interaction was functionally relevant in the activation of the S-phase checkpoint. For this purpose, we examined PCNA foci in CPTtreated or irradiated Hus1 cells because PCNA foci co-localize with DNA replication foci $(34,35)$ and because PCNA is not involved in the initiation step in DNA replication as RPA does to interact with the DNA polymerase $\alpha$-primase complex, but rather functions as a DNA polymerase $\delta$ accessory factor promoting DNA chain elongation (36). In low doses of CPTtreated $(\leqslant 0.5 \mu \mathrm{M})$ or irradiated $(\leqslant 10 \mathrm{~Gy})$ cells, the number of PCNA foci did not show any apparent change compared with non-treated control cells (data not shown). However, as expected, PCNA foci were clearly reduced in Hus 1 wild type cells at $3 \mathrm{~h}$ after exposure to higher doses of CPT $(2 \mu \mathrm{M})$ or IR (30 Gy), and were not reduced in Hus1-deficient cells at the same time after exposure to such doses of CPT or IR (Fig. 3A and B). When Hus1 was reintroduced into Hus1-deficient cells, a reduction of PCNA foci again was observed after exposure to such doses of CPT or IR (Fig. 3B). To confirm the effects of Hus 1 on replication foci of PCNA, we examined the levels of PCNA bound to chromatin in CPT-treated or irradiated Hus1 cells because PCNA bound to chromatin in the $S$ phase is resistant to detergent extraction (34,37). After exposure of cells to CPT $(2 \mu \mathrm{M})$ or IR $(30 \mathrm{~Gy})$, the level of PCNA bound to chromatin was dramatically reduced in wild type cells but was not affected in Hus1-deficient cells
(Fig. 3C). When Hus1 was reintroduced into Hus1-deficient cells, chromatin association of PCNA was reduced again following the same doses of CPT or IR exposure (data not shown), confirming that Hus 1 plays a key role in the release of PCNA from chromatin after DNA damage. These results suggest, consistent with the gradient results (Fig. 2), that Hus1 is responsible for the replication function of PCNA in mammalian cells after CPT treatment or IR.

\section{Hus1 is required for Rad9 phosphorylation following exposure of cells to CPT or IR}

Rad9 is phosphorylated in response to DNA damage, and this phosphorylation is essential for the 9-1-1 complex formation $(38,39)$. To test the effect of Hus 1 on Rad9 phosphorylation, we examined Rad9 phosphorylation in CPT $(2 \mu \mathrm{M})$-treated or irradiated (30 Gy) Hus 1 cells. Consistent with previous reports $(15,39)$, Rad9 was detected as a slower migrating band in CPT-treated or irradiated Hus1 wild type cells (Fig. 4A), suggesting Rad9 phosphorylation after exposure of cells to CPT or IR. However, no slower migrating band of Rad9 was detected in CPT-treated or irradiated Hus1-deficient cells (Fig. 4A). When Hus1 was reintroduced into Hus1-deficient cells, the CPT or IR induced slower migrating band of Rad9 was detected again (Fig. 4A), indicating that Hus1 was required for Rad9 phosphorylation. Similar results were reported by others in Hus1-deficient cells following other 
A

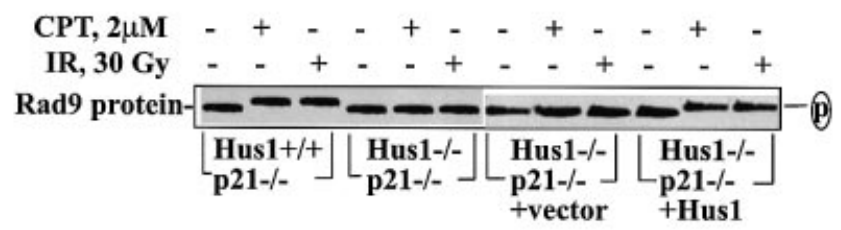

B

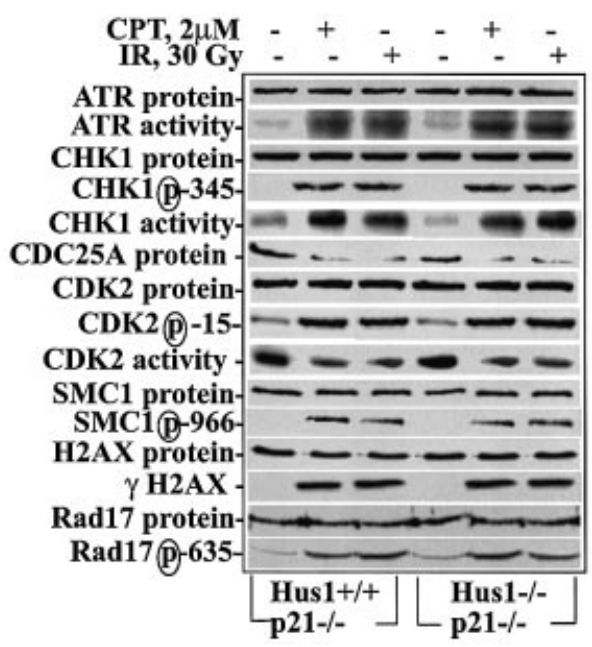

Figure 4. Hus1-deficient cells do not show Rad9 phosphorylation but show normal activation of ATR/CHK1 kinases following exposure to CPT or IR. (A) Defective Rad9 phosphorylation in CPT $(2 \mu \mathrm{M})$-treated or irradiated (30 Gy) Hus1-deficient cells. Rad9 protein was analyzed from the whole cell lyses prepared by RIPA lysis buffer $(50 \mathrm{mM}$ Tris- $\mathrm{HCl}$, pH 7.4; $1 \%$ NP$40 ; 0.25 \%$ sodium deoxycholate; $150 \mathrm{mM} \mathrm{NaCl} ; 1 \mathrm{mM}$ EGTA; $1 \mathrm{mM}$ PMSF; $1 \mu \mathrm{g} / \mathrm{ml}$ each aprotinin, leupeptin, pepstatin; $1 \mathrm{mM} \mathrm{Na}_{3} \mathrm{VO}_{4} ; 1 \mathrm{mM}$ $\mathrm{NaF}$. (B) Equal levels of activity and phosphorylation of the proteins tested in Hus1 wild type and Hus1-deficient cells following exposure to CPT $(2 \mu \mathrm{M})$ or IR $(30 \mathrm{~Gy})$. Cell extracts were prepared from the cells either treated with CPT for $3 \mathrm{~h}$ or at $3 \mathrm{~h}$ after IR (30 Gy). The activities of ATR and CHK1 were measured as described in Materials and Methods. SMC1 and phosphorylated SMC1 were measured with nuclear extracts. Phosphorylated CHK1, CDC25A Rad17, phosphorylated Rad17, H2AX and phosphorylated $\mathrm{H} 2 \mathrm{AX}$ were measured with the whole cell lyses prepared by RIPA lysis buffer.

types of DNA damage induced by UV or hydroxyurea (HU) (31). The requirement of Hus1 for Rad9 phosphorylation following DNA damage can be explained by two possible mechanisms: either the kinase that is responsible for $\operatorname{Rad} 9$ phosphorylation is not activated; or the kinase is activated but the substrate is not recognized by the kinase. To discover which mechanism explains the failure of Rad9 phosphorylation in Hus1-deficient cells, we tested activities of the kinases that were possible for Rad9 phosphorylation in CPT-treated or ionizing irradiated Hus 1 cells.

\section{Both the ATR/CHK1 and the ATM pathways are activated normally in Hus1-deficient cells following exposure of cells to CPT or IR}

CPT-induced S checkpoint is regulated mainly by the ATR/ CHK1 pathway $(24,26,28)$. IR-induced $S$ checkpoint is also partially regulated by the ATR/CHK1 pathway $(29,33)$. Hus 1 affects the ATR/CHK1 pathway-regulated $\mathrm{S}$ checkpoint in UV-irradiated cells $(22,23)$ and, in general, it is believed that
Hus1, as a sensor component, activates checkpoint following DNA damage. We therefore tested activation of the ATR/ CHK1 pathway in CPT-treated or irradiated Hus1 cells. Unexpectedly, ATR activity, CHK1 phosphorylation and CHK1 activity remained at the same levels in both Hus1deficient and Hus1 wild type cells following exposure to CPT $(2 \mu \mathrm{M})$ or IR (30 Gy) (Fig. 4B). The CDC25A/CDK2 pathway is the downstream target of CHK1 for regulating the CPT- or IR-induced S checkpoint response $(27,28,33)$. We measured CDC25A protein levels, phosphorylated CDK2 and CDK2 activity to test whether Hus1 affected these proteins in these CPT-treated or irradiated cells. All changes in the proteins were at similar levels in Hus1-deficient cells and in Hus1 wild type cells following CPT treatment or IR (Fig. 4B), confirming that the CHK1/CDC25A/CDK2 pathway is activated normally in CPT-treated or irradiated Hus1-deficient cells.

SMC1 is another potential substrate of ATR following DNA damage $(32,40)$. We tested the phosphorylated levels of SMC1 in these Hus1 cells following CPT $(2 \mu \mathrm{M})$ treatment or IR (30 Gy). The results showed that both Hus1-deficient and Hus1 wild type cells showed similar phosphorylation of SMC1 (Fig. 4B), indicating that the impaired S checkpoint in Hus1deficient cells is not related to SMC1 phosphorylation. Rad17 is phosphorylated by ATR following DNA damage (31). Rad17, which is a homolog of the RFC subunit, forms a complex with RFC as a clamp loader that promotes binding of the 9-1-1 complex to damaged DNA (41). We measured the levels of phosphorylated Rad17 in CPT-treated or irradiated Hus1 cells. Hus1 wild type and Hus1-deficient cells showed the similar levels of phosphorylated Rad17 following exposure to CPT or IR (Fig. 4B), suggesting that ATR is normally activated in Hus1-deficient cells. To verify that ATR is normally activated in CPT-treated or irradiated Hus1deficient cells, we tested H2AX in these CPT-treated or irradiated Hus1 cells because H2AX is another substrate of ATR and is phosphorylated following DNA damage (42). The results showed that both Hus1-deficient and Hus1 wild type cells had phosphorylated H2AX similarly (Fig. 4B), indicating that ATR is normally activated in CPT-treated or irradiated Hus1-deficient cells.

Although the CPT-induced S checkpoint is independent of the ATM pathway $(24,26,28), \operatorname{Rad} 9$ is phosphorylated by PKC $\delta$ in an ATM-dependent manner following DNA damage $(38,39)$, and the ATM pathway is a main component for regulating the IR-induced $S$ checkpoint $(5,32,40,43-45)$. We therefore measured the activities of ATM/CHK2 kinases. Again, no differences were observed in the activities of ATM and CHK2 after exposure of cells to CPT or IR between Hus1-deficient and wild type cells (data not shown).

Because ATR or ATM is activated normally in Hus1deficient cells following exposure to CPT or IR, the defect in Rad9 phosphorylation can be explained in two possible ways. Either the kinase responsible for Rad9 phosphorylation is not ATR or ATM and cannot be activated in Hus1-deficient cells, or Rad9 in Hus1-deficient cells is in a form not amenable to phosphorylation (altered conformation or complex formation). We favor the second explanation because the 9-1-1 complex cannot form without Hus1. However, we remain open to the possibility that PKC $\delta$ or other kinases are affected directly by the loss of Hus1 after exposure of cells to CPT or IR. 


\section{DISCUSSION}

It has been known for almost 30 years that DNA damage inhibits chain elongation of DNA replication (7), but little is known about the mechanisms involved in this aspect of the $S$ checkpoint. Because the inhibition of chain elongation is more resistant than the inhibition of replicon initiation to DNA damage, the inhibition of chain elongation is considered a passive process. The data presented in this study clearly demonstrate that, similar to DNA damage-induced inhibition of replicon initiation, the inhibition of chain elongation is also a cellular active response to DNA damage, which depends on Hus 1 and is associated with PCNA function. Besides Hus1 (21), human Rad9 and Rad17/RFC also interact directly with PCNA (46,47). Because Hus1 participates in the 9-1-1 complex (46), which associates with the Rad17 complex (41) as part of the response to DNA damage, it is possible that interference with PCNA in response to CPT- or IR-induced DNA damage is also involved in Rad1, Rad9 and Rad17. Further experiments are required to test this hypothesis.

Both CPT and IR can induce DNA double strand breaks (DSBs), but there are some different characteristics between CPT- and IR-induced S checkpoints. DNA replication in mammalian cells is much more sensitive to CPT than to IR at similar levels of induction of DNA DSBs. CPT at $2 \mu \mathrm{M}$ induced DNA DSB is relative to IR 4 Gy dose (48). Cells treated with this dose of CPT show the strong inhibition of DNA replication $(24,27)$ in both replicon initiation and chain elongation (Fig. 2). Cells irradiated with 4 Gy show little inhibition of DNA replication (49) and no inhibition of chain elongation (our unpublished data). The different sensitivities to the S checkpoint between CPT-treated cells and irradiated cells indicate that CPT- or IR-induced inhibition of DNA replication is not directly caused by induction of DNA DSBs, and other factors such as conformation changes of DNA replication machinery must be involved. Such factors could be affected easily by CPT treatment and would need much higher doses of IR to get a similar effect, which might also explain why CPT-induced S checkpoint is much more important than IR-induced S checkpoint for protecting cells from killing (Fig. 1D) (27). These hypotheses need to be tested further.

In addition, regulation of the $\mathrm{S}$ checkpoint induced by CPT is different from that induced by IR. CPT-induced S checkpoint regulation is ATM pathway independent but ATR/ CHK1 pathway dependent $(24,26,28)$. IR-induced S checkpoint regulation is dependent on both the ATM and the ATR/ CHK1 pathways $(5,29,32,33,40,43-45,50)$. The ATMdependent pathway regulates the fast response following IR $(29,51,52)$ and the ATR-dependent pathway regulates the slow response following IR $(29,52)$. At $3 \mathrm{~h}$ after IR the $\mathrm{S}$ checkpoint is regulated mainly by the ATR/CHK1 pathway (29). Although Hus1-deficient cells show normal activation of ATR/CHK1 following exposure to CPT and IR, the specific gene-targeting inhibition of CHK1 can reverse the inhibition of DNA replication in either CPT $(2 \mu \mathrm{M})$-treated $(24,27)$ or irradiated (30 Gy) Hus1 wild type cells (29), indicating that this Hus1-dependent process is involved in the CHK1 pathway but is not an upstream regulator of this pathway and might be a downstream effector.

The association of the 9-1-1 complex with chromatin is a very early step in the response to DNA damage (53). Although
Rad17 phosphorylation after DNA damage is dependent on ATM and ATR $(31,54)$, phosphorylation of Rad17 is not required for 9-1-1 complex loading onto chromatin, and the chromatin associations of Rad17 and ATR are largely independent (31). These results suggest that the association of the 9-1-1 complex or Rad17 with chromatin is independent of ATR and/or ATM. If association of the 9-1-1 complex with chromatin was the signal transducer required to activate the ATR and/or ATM pathway, removal of any component of the complexes would result in a failure to activate these kinases, and in an abrogation of all checkpoint responses associated with this activation. However, we show in this study that Hus1-deficient cells show a normal inhibition of replicon initiation of DNA replication following exposure to CPT or IR. Similarly, the mutant version of $M E C 3$, the budding yeast homolog of Hus1, shows only partial checkpoint defects $(55,56)$. It was reported recently that RPA binding to damaged DNA is an early event required for the activation of the ATRATRIP complex to phosphorylate $\operatorname{Rad} 17$ (57). This is also consistent with the hypothesis that the 9-1-1 complex is not a signal transducer required for the activation of the major checkpoint kinases ATR and ATM following DNA DSBinducing agents such as CPT or IR.

The ATR/CHK1 pathway is involved in the regulations of the $\mathrm{S}$ checkpoint induced by all types of DNA damageinducers including DSB-inducing agents such as CPT or IR and other types of DNA damage-inducers such as UV or HU. However, CPT- or IR-induced S checkpoint regulation is much different from UV or HU-induced $\mathrm{S}$ checkpoint regulation. CPT- or IR-induced CHK1 phosphorylation does not require Hus1 (Fig. 4B), but UV does (22). CPT- or IRinduced Rad17 phosphorylation does not require Hus1 (Fig. 4B), but UV or HU does (31). These results indicate that the kinase responsible for Rad17 and CHK1 phosphorylation does not require the assistance of Hus1 for its activation following exposure of cells to CPT or IR but does require the assistance of Hus1 for its activation following exposure of cells to UV or HU. Although Hus1 is required for Rad9 phosphorylation following exposure of cells to CPT or IR (Fig. 4A), it does not seem possible that the failure of $\operatorname{Rad} 9$ phosphorylation in Hus1-deficient cells following exposure to CPT or IR is because of inactivation of the kinase responsible for Rad9 phosphorylation. It might be the reason that failure to form the 9-1-1 complex without Hus1 results in failure to recognize the substrate by its kinase. These results suggest that, different from the role of Hus1 in HU- or UV-induced S checkpoint that serves both as signal transducer as well as effector (58), the role of Hus1 in CPT- or IR-induced S checkpoint serves only as an effector as shown in this study. However, at present, we cannot completely exclude the possibility that multiple sensors exist to activate $S$ checkpoint in mammalian cells following exposure to CPT or IR, and the role of Hus 1 as a sensor could be overlapped by other sensors.

Formation of the 9-1-1 complex is a very fast process but disassembling of the complex is a very slow process (56). It might be that formation of the 9-1-1 complex needs only changes of DNA conformation, but disassembling of this complex needs more processes including changes of DNA conformation and modification of this complex such as phosphorylation. Modifications such as Rad9 phosphorylation might facilitate the complex to replace PCNA in the DNA 
replication machinery, thus stopping the elongation of DNA replication. Meanwhile, other substrates of ATR or ATM kinase activate their targets acting to stop the initiation steps of DNA replication following exposure of cells to CPT or IR.

\section{ACKNOWLEDGEMENTS}

We thank Dr Leder for the Hus1 cell lines, Dr Elledge for phosphorylated Rad17 antibody, Dr Qin for SMC1 antibodies, Nancy Mott for help in the preparation of the manuscript and Peggy Mammen for help in the laboratory work. This work is supported by NIH Grants CA76203, CA56706 and P30-CA56036.

\section{REFERENCES}

1. Paulovich,A.G. and Hartwell,L.H. (1995) A checkpoint regulates the rate of progression through $\mathrm{S}$ phase in $S$. cerevisiae in response to DNA damage. Cell, 82, 841-847.

2. Paulovich,A.G., Toczyski,D.P. and Hartwell,L.H. (1997) When checkpoints fail. Cell, 88, 315-321.

3. Eller,M.S., Ostrom,K. and Gilchrest,B.A. (1996) DNA damage enhances melanogenesis. Proc. Natl Acad. Sci. USA, 93, 1087-1092.

4. Zhou,B.-B.S. and Elledge,S.J. (2000) The DNA damage response: putting checkpoints in perspective. Nature, 408, 433-439.

5. Painter,R.B. and Young,B.R. (1980) Radiosensitivity in ataxiatelangiectasia: a new explanation. Proc. Natl Acad. Sci. USA, 77, 7315-7317.

6. Xu,B., Kim,S.-T. and Kastan,M.B. (2001) Involvement of Brca1 in S-phase and G2-phase checkpoints after ionizing irradiation. Mol. Cell. Biol., 21, 3445-3450.

7. Watanabe,I. (1974) Radiation effects on DNA chain growth in mammalian cells. Radiat. Res., 58, 541-556.

8. Painter,R.B. and Young,B.R. (1975) X-ray-induced inhibition of DNA synthesis in Chinese hamster ovary, human HeLa and mouse L cells. Radiat. Res., 64, 648-656.

9. Painter,R.B. and Young,B.R. (1976) Formation of nascent DNA molecules during inhibition of replicon initiation in mammalian cells. Biochim. Biophys. Acta, 418, 146-153.

10. Wang,X. and Iliakis,G. (1993) Persistent inhibition of DNA synthesis after radiation exposure in four clones obtained from rat embryo fibroblasts by transfection with the oncogenes H-ras plus v-myc. Int. J. Radiat. Biol., 64, 165-168.

11. Guan,J., DiBiase,S. and Iliakis,G. (2000) The catalytic subunit DNAdependent protein kinase (DNA-PKcs) facilitates recovery from radiation-induced inhibition of DNA replication. Nucleic Acids Res., 28 $1183-1192$.

12. Heffernan,T.P., Simpson,D.A., Frank,A.R., Heinloth,A.N., Paules,R.S., Cordeiro-Stone,M. and Kaufmann,W.K. (2002) An ATR- and Chk1dependent S checkpoint inhibits replicon initiation following UVCinduced DNA damage. Mol. Cell. Biol., 22, 8552-8561.

13. Aravind,L., Walker,D.R. and Koonin,E.V. (1999) Conserved domains in DNA repair proteins and evolution of repair systems. Nucleic Acids Res. 27, 1223-1242.

14. St. Onge,R.P., Udell,C.M., Casselman,R. and Davey,S. (1999) The human $\mathrm{G} 2$ checkpoint control protein hRAD9 is a nuclear phosphoprotein that forms complexes with hRAD1 and hHUS1. Mol. Biol. Cell, 10, 1985-1995.

15. Volkmer,E. and Karnitz,L.M. (1999) Human homologs of Schizosaccharomyces pombe Rad1, Hus1 and Rad9 form a DNA damage-responsive protein complex. J. Biol. Chem., 274, 567-570.

16. Rauen,M., Burtelow,M.A., Dufault,V.M. and Karnitz,L.M. (2000) The human checkpoint protein hRad17 interacts with the PCNA-like proteins hRad1, hHus1 and hRad9. J. Biol. Chem., 275, 29767-29771.

17. Caspari,T., Dahlen,M., Kanter-Smoler,G., Lindsay,H.D., Hofmann,K., Papadimitriou,K., Sunnerhagen,P. and Carr,A.M. (2000) Characterization of Schizosaccharomyces pombe Hus1: a PCNA-related protein that associates with Rad1 and Rad9. Mol. Cell. Biol., 74, $1254-1262$.

18. O'Connell,M.J., Walworth,N.C. and Carr,A.M. (2000) The G2-phase DNA-damage checkpoint. Trends Cell Biol., 10, 296-303.
19. Enoch,T., Carr,A.M. and Nurse,P. (1992) Fission yeast genes involved in coupling mitosis to completion of DNA replication. Genes Dev., 6 , 2035-2046.

20. Weiss,R.S., Enoch,T. and Leder,P. (2000) Inactivation of mouse Hus1 results in genomic instability and impaired responses to genotoxic stress. Genes Dev., 14, 1886-1898.

21. Komatsu,K., Wharton,W., Hang,H., Wu,C., Singh,S., Lieberman,H.B., Pledger,W.J. and Wang,H.-G. (2000) PCNA interacts with hHus1/hRad9 in response to DNA damage and replication inhibition. Oncogene, 19, 5291-5297.

22. Weiss,R.S., Matsuoka,S., Elledge,S.J. and Leder,P. (2002) Hus1 acts upstream of Chk1 in a mammalian DNA damage response pathway. Curr. Biol., 12, 73-77.

23. Weiss,R.S., Leder,P. and Vaziri,C. (2003) Critical role for mouse Hus1 in an S-phase DNA damage cell cycle checkpoint. Mol. Cell. Biol., 23, 791-803.

24. Wang,H., Wang,X., Zhou,X.Y., Chen,D.J., Li,G.C., Iliakis,G. and Wang,Y. (2002) Ku affects the Ataxia and Rad 3-related/Chk1dependent S-phase checkpoint response after camptothecin treatment. Cancer Res., 62, 2483-2487.

25. Wan,S., Capasso,H. and Walworth,N.C. (1999) The topoisomerase I poison camptothecin generates a Chk1 dependent DNA damage checkpoint signal in fission yeast. Yeast, 15, 821-828.

26. Cliby,W.A., Lewis,K.A., Lilly,K.K. and Kaufmann,S.H. (2002) S Phase and G2 arrests induced by topoisomerase I poisons are dependent on ATR kinase function. J. Biol. Chem., 277, 1599-1606.

27. Wang,J.-L., Wang,X., Wang,H., Iliakis,G. and Wang,Y. (2002) CHK1-regulated S-phase checkpoint response reduces camptothecin cytotoxicity. Cell Cycle, 1, 267-272.

28. Xiao,Z., Chen,Z., Gunasekera,A.H., Sowin,T.J., Rosenberg,S.H., Fesik,S. and Zhang,H. (2003) Chk1 mediates S and G2 arrest through Cdc25A degradation in response to DNA-damaging agents. J. Biol. Chem., 278, 21767-21773.

29. Zhou,X.Y., Wang,X., Hu,B., Guan,J., Iliakis,G. and Wang,Y. (2002) An ATM-independent $\mathrm{S}$ phase checkpoint response involves CHK1 pathway. Cancer Res., 62, 1598-1603.

30. Wang,Y., Cheong,N. and Iliakis,G. (1993) Persistent inhibition of DNA synthesis in irradiated rat embryo fibroblasts expressing the oncogenes $\mathrm{H}$-ras plus v-myc derives from inhibition of replicon initiation and is mitigated by staurosporine. Cancer Res., 53, 1213-1217.

31. Zou,L., Cortez,D. and Elledge,S.J. (2002) Regulation of ATR substrate selection by Rad17-dependent loading of Rad9 complexes onto chromatin. Genes Dev., 16, 198-208.

32. Yazdi,P.T., Wang,Y., Zhao,S., Patel,N., Lee,E.Y.-H.P. and Qin,J. (2002) SMC1 is a downstream effector in the ATM/NBS1 branch of the human S-phase checkpoint. Genes Dev., 16, 571-582.

33. Zhao,H., Watkins,J.L. and Piwnica-Worms,H. (2002) Disruption of the checkpoint kinase $1 /$ cell division cycle $25 \mathrm{~A}$ pathway abrogates ionizing radiation-induced S and G2 checkpoints. Proc. Natl Acad. Sci. USA, 99, $14795-14800$.

34. Bravo,R. and Macdonald-Bravo,H. (1987) Existence of two populations of cyclin/proliferating cell nuclear antigen during the cell cycle: association with DNA replication sites. J. Cell Biol., 105, 1549-1554.

35. Humbert,C., Santisteban,M.S., Usson,Y. and Robert-Nicoud,M. (1992) Intranuclear co-location of newly replicated DNA and PCNA by simultaneous immunofluorescent labeling and confocal microscopy in MCF-7 cells. J. Cell. Sci., 103, 97-103.

36. Waga,S. and Stillman,B. (1998) The DNA replication fork in eukaryotic cells. Annu. Rev. Biochem., 67, 721-751.

37. Li,R., Hannon,G.J., Beach,D. and Stillman,B. (1996) Subcellular distribution of p21 and PCNA in normal and repair-deficient cells following DNA damage. Curr. Biol., 6, 189-199.

38. Yoshida,K., Wang,H.-G., Miki,Y. and Kufe,D. (2003) Protein kinase C $\delta$ is responsible for constitutive and DNA damage-induced phosphorylation of Rad9. EMBO J., 22, 1431-1441.

39. Chen,M.-J., Lin,Y.-T., Lieberman,H.B., Chen,G. and Lee,E.Y.-H.P. (2001) ATM-dependent phosphorylation of human Rad9 is required for ionizing radiation-induced checkpoint activation. J. Biol. Chem., 276, $16580-16586$.

40. Kim,S.-T., Xu,B. and Kastan,M.B. (2002) Involvement of the cohesin protein, Smc1, in Atm-dependent and independent responses to DNA damage. Genes Dev., 16, 560-570. 
41. Rauen,M., Burtelow,M.A., Dufault,V.M. and Karnitz,L.M. (2000) The human checkpoint protein hRad17 interacts with the PCNA-like protein hRad1, hHus1 and hRad9. J. Biol. Chem., 275, 29767-29771.

42. Ward,I.M. and Chen,J. (2001) Histone H2AX is phosphorylated in an ATR-dependent manner in response to replicational stress. J. Biol. Chem., 276, 47759-47762.

43. Houldsworth,J. and Lavin,M.F. (1980) Effect of ionizing radiation on DNA synthesis in ataxia telangiectasia cells. Nucleic Acids Res., 8 , 3709-3720.

44. Falck,J., Mailand,N., Syljuasen,R.G., Bartek,J. and Lukas,J. (2001) The ATM-Chk2-Cdc25A checkpoint pathway guards against radioresistant DNA synthesis. Nature, 410, 842-847.

45. Falck,J., Petrini,J.H.J., Williams,B.R., Lukas,J. and Bartek,J. (2002) The DNA damage-dependent intra-S phase checkpoint is regulated by parallel pathways. Nature Genet., 30, 290-294.

46. Burtelow,M.A., Roos-Mattjus,P.M.K., Rauen,M., Babendure,J.R. and Karnitz,L.M. (2001) Reconstitution and molecular analysis of the hRad9hHus1-hRad1 (9-1-1) DNA damage responsive checkpoint complex. J. Biol. Chem., 276, 25903-25909.

47. Dahm,K. and Hubscher,U. (2002) Colocalization of human Rad17 and PCNA in late S phase of the cell cycle upon replication block. Oncogene, 21, 7710-7719.

48. Wang,Y., Perrault,A.R. and Iliakis,G. (1997) Down-regulation of DNA replication in extracts of camptothecin-treated cells: activation of an S-phase checkpoint? Cancer Res., 57, 1654-1659.

49. Wang,Y. and Iliakis,G. (1992) Prolonged inhibition by x-rays of DNA synthesis in cells obtained by transformation of primary rat embryo fibroblasts with oncogenes H-ras and v-myc. Cancer Res., 52, 508-514.
50. Guo,C.Y., Brautigan,D.L. and Larner,J.M. (2002) Ionizing radiation activates nuclear protein phosphatase-1 by ATM-dependent dephosphorylation. J. Biol. Chem., 277, 41756-41761.

51. Bakkenist,C.J. and Kastan,M.B. (2003) DNA damage activates ATM through intermolecular autophosphorylation and dimer dissociation. Nature, 421, 499-506.

52. Brown,E.J. and Baltimore,D. (2003) Essential and dispensable roles of ATR in cell cycle arrest and genome maintenance. Genes Dev., 17, 615-628.

53. Roos-Mattjus,P., Vroman,B.T., Burtelow,M.A., Rauen,M., Eapen,A.K. and Karnitz,L.M. (2002) Genotoxin-induced Rad9-Hus1-Rad1 (9-1-1) chromatin association is an early checkpoint signaling event. J. Biol. Chem., 277, 43809-43812.

54. Bao,S., Tibbetts,R.S., Brumbaugh,K.M., Fang,Y., Richardson,D.A., Ali,A., Chen,S.M., Abraham,R.T. and Wang,X.F. (2001) ATR/ATMmediated phosphorylation of human $\operatorname{Rad} 17$ is required for genotoxic stress responses. Nature, 411, 969-974.

55. Giannattasio,M., Sommariva,E., Vercillo,R., Lippi-Boncambi,F., Liberi,G., Foiani,M., Plevani,P. and Muzi-Falconi,M. (2002) A dominant-negative MEC3 mutant uncovers new functions for the Rad17 complex and Tel1. Proc. Natl Acad. Sci. USA, 99, 12997-13002.

56. Giannattasio,M., Sabbioneda,S., Minuzzo,M., Plevani,P. and Muzi-Falconi,M. (2003) Correlation between checkpoint activation and in vivo assembly of the yeast checkpoint complex Rad17-Mec3-Ddc1. J. Biol. Chem., 278, 22303-22308.

57. Zou,L. and Elledge,S.J. (2003) Sensing DNA damage through ATRIP recognition of RPA-ssDNA complexes. Science, 300, 1542-1548.

58. Kai,M. and Wang,T.S.-F. (2003) Checkpoint activation regulates mutagenic translesion synthesis. Genes Dev., 17, 64-76. 